\title{
Oxygenase Domain of Drosophila melanogaster Nitric Oxide Synthase: Unique Kinetic Parameters Enable a More Efficient NO Release ${ }^{\dagger}$
}

\author{
Sougata Sinha Ray,,$\perp$ Jesús Tejero," Zhi-Qiang Wang," Tanmay Dutta, ${ }^{\ddagger}$ Arindam Bhattacharjee,,${ }^{\ddagger}$ Michael Regulski,, \\ Tim Tully, ${ }^{\S}$ Sanjay Ghosh, ${ }^{*, *}$ and Dennis J. Stuehr*,l \\ Department of Biochemistry, University College of Sciences, Calcutta University, West Bengal 700 019, India, \\ Cold Spring Harbor Laboratory, Cold Spring Harbor, New York, and Department of Pathobiology, \\ The Lerner Research Institute, The Cleveland Clinic, Cleveland, Ohio 44195
}

Received April 27, 2007; Revised Manuscript Received August 3, 2007

\begin{abstract}
Although nitric oxide (NO) is important for cell signaling and nonspecific immunity in the fruit fly Drosophila melanogaster, little is known about its single NO synthase (dNOS). We expressed the oxygenase domain of dNOS (dNOSoxy), characterized its spectroscopic, kinetic, and catalytic properties, and interpreted them in light of a global kinetic model for NO synthesis. Single turnover reactions with ferrous dNOSoxy showed it could convert Arg to $N^{\prime \omega}$-hydroxy-L-arginine (NOHA), or NOHA to citrulline and $\mathrm{NO}$, when it was given $6 R$-tetrahydrobiopterin and $\mathrm{O}_{2}$. The dNOSoxy catalyzed Arg hydroxylation and NOHA oxidation at rates that matched or exceeded the rates catalyzed by the three mammalian NOSoxy enzymes. Consecutive heme-dioxy, ferric heme-NO, and ferric heme species were observed in the NOHA reaction of dNOSoxy, indicating that its catalytic mechanism is the same as in the mammalian NOS. However, NO dissociation from dNOSoxy was 4 to 9 times faster than that from the mammalian NOS enzymes. In contrast, the dNOSoxy ferrous heme-NO complex was relatively unreactive toward $\mathrm{O}_{2}$ and in this way was equivalent to the mammalian neuronal NOS. Our data show that dNOSoxy has unique settings for the kinetic parameters that determine its NO synthesis. Computer simulations reveal that these unique settings should enable dNOS to be a more efficient and active NO synthase than the mammalian NOS enzymes, which may allow it to function more broadly in cell signaling and immune functions in the fruit fly.
\end{abstract}

Nitric oxide synthase enzymes (NOS, EC 1.14.13.39) convert L-arginine to nitric oxide (NO) and citrulline by catalyzing a stepwise, NADPH- and $\mathrm{O}_{2}$-dependent reaction that forms $N^{\prime \omega}$-hydroxy-L-arginine $\left(\mathrm{NOHA}^{1}\right)$ as an intermediate (Scheme 1) (1-3). Three NOS isozymes are expressed in mammals (neuronal or nNOS, inducible or iNOS, and endothelial or eNOS), and they differ with regard to their expression, catalysis, and cellular localization $(2,4-7)$. All NOSs comprise attached heme-containing (oxygenase) and

This work was supported by Department of Science and Technology (DST), Govt. of India, National Institutes of Health Grants GM51491, CA53914, and HL76491 (to D.J.S.), American Heart Association Beginning Grant-in-Aid 0565297B (to Z-Q.W.), and American Heart Association postdoctoral fellowship 0625632B (to J.T.).

* To whom correspondence should be addressed: Department of Pathobiology, NC-22, Lerner Research Institute, The Cleveland Clinic, 9500 Euclid Ave., Cleveland, OH 44195. Phone: (216)-445-6950. Fax: (216)-444-9329. E-mail: stuehrd@ccf.org (D.J.S.). Department of Biochemistry, University College of Sciences, Calcutta University, 35 Ballygunge Circular Road, Kolkata, West Bengal 700 019, India. Phone: +91-33-2461-5445. Fax: +91-33-2461-4849. E-mail: sgbioc@ caluniv.ac.in; ghoshs71@ hotmail.com (S.G.).

$\doteqdot$ University of Calcutta.

$\S$ Cold Spring Harbor Laboratory.

"The Cleveland Clinic.

${ }^{\perp}$ S.S.R is a Senior Research Fellow of Council for Scientific and Industrial Research (CSIR), Govt. of India.

${ }^{1}$ Abbreviations: CaM, human calmodulin; EPPS, 4-(2-hydroxyethyl)-1-piperazinepropanesulfonic acid; NOS, nitric oxide synthase; nNOS, rat neuronal NOS; NOSoxy, the oxygenase domain of a given NOS; NOHA, $N^{\prime \omega}$-hydroxy-L-arginine.
Scheme 1

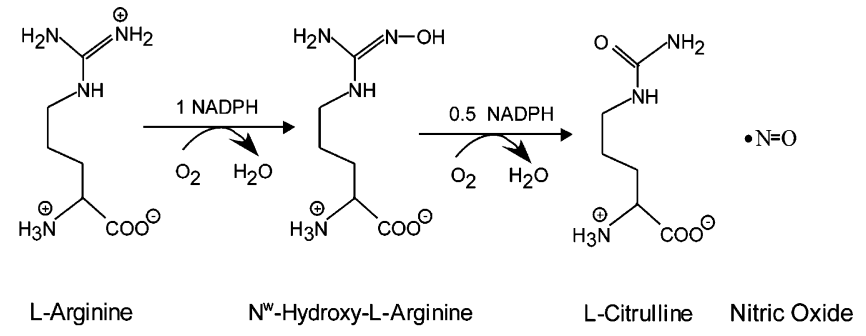

flavin-containing (reductase) domains that are connected by a central calmodulin $(\mathrm{CaM})$ binding sequence $(8-13)$. Because NOS oxygenase and reductase domains can fold and function independently, they have been overexpressed and subjected to detailed structural, kinetic, and regulatory studies (14-16), along with some NOS oxygenase-like enzymes that are present in bacteria $(17-19)$.

The insect Drosophila melanogaster expresses a single NOS enzyme (dNOS) that participates in the developmental, behavioral, and host defense pathways of the fruit fly (2024). However, besides its generation of $\mathrm{NO}$ in a $\mathrm{Ca}^{2+}-$ and CaM-dependent manner $(25,26)$, similar to the mammalian eNOS and nNOS enzymes, little is known regarding the catalytic properties of dNOS. A more detailed characterization stands to broaden our understanding of NOS structurefunction relationships and could help to clarify NOS functions in the fruit fly. To address this, we characterized 
the catalytic and kinetic properties of the dNOS oxygenase domain (dNOSoxy) after its overexpression in E. coli. Our results show that dNOSoxy is most similar to the mammalian nNOS but has kinetic features that distinguish it from the mammalian NOS enzymes. These findings, along with results in the accompanying article on the reductase domain of dNOS, suggest that dNOS evolved to support a more efficient and active NO release than do the mammalian enzymes.

\section{EXPERIMENTAL PROCEDURES}

Materials. All reagents and materials were obtained from Sigma, Alexis Biochemicals, and Amersham Biosciences, unless noted otherwise.

dNOSoxy Construct Generation. The pCWori vector containing the $5^{\prime}$ hexa-His tagged dNOS full-length construct (4050 bp) within NdeI and HindIII restriction sites, as described in (26), was used to generate a $5^{\prime}$ hexa-His tagged construct of the dNOS oxygenase domain and the adjoining CaM binding sequence (dNOSoxy). This construct ends at Ser683. To create the stop codon after Ser683, the following primers were used to amplify a fragment of dNOS: 5'ACGGTGGCGCTGAAGATGCAACTGG-3' and 5'-GATAAGCTTTTACGATTTGCCAGTTTCGGTGGC-3'. The second primer contains the stop codon in bold followed by the underlined HindIII restriction site. This PCR product was subcloned into a PCR-4 vector (Invitrogen) and was digested with BsiWI (located downstream from the forward primer) and HindIII (both are unique sites) and cloned into the pCWori plasmid containing dNOS after it had been digested with the same enzymes. Positive clones of dNOSoxy were identified by restriction analysis.

Expression and Purification of dNOSoxy. The dNOSoxy protein was expressed in recombinant E.coli Rosetta cells using the pCWori plasmid as done with the mammalian NOSoxy proteins (34). Transformed bacteria were grown at $37{ }^{\circ} \mathrm{C}$ in $3 \mathrm{~L}$ of terrific broth supplemented with $100 \mathrm{mg} / \mathrm{L}$ ampicillin. Protein expression was induced when the cultures reached an $\mathrm{OD}_{600}$ of 0.8 to 1 by adding $1 \mathrm{mM}$ isopropyl- $\beta$ D-thiogalactoside. After further growth at room temperature for $24 \mathrm{~h}$, the cells were harvested and resuspended in buffer A (40 mM EPPS, $150 \mathrm{mM} \mathrm{NaCl}$, and $10 \%$ glycerol) containing $1 \mathrm{mM}$ L-Arg, $10 \mu \mathrm{M} \mathrm{H}_{4} \mathrm{~B}, 0.5 \mathrm{mg} / \mathrm{mL}$ each of leupeptin and pepstatin, $1 \mathrm{mg} / \mathrm{mL}$ lysozyme, and $1 \mathrm{mM}$ phenylmethylsulfonyl fluoride. Cells were lysed by freezethawing three times in liquid nitrogen followed by sonication for five 45-s pulses with a 1-min rest on ice between pulses. The cell lysate was centrifuged at $4{ }^{\circ} \mathrm{C}$ for $30 \mathrm{~min}$, and the cell-free supernatant was precipitated by adding $50 \%(\mathrm{w} / \mathrm{v})$ ammonium sulfate. The precipitant was centrifuged at $4{ }^{\circ} \mathrm{C}$ for $30 \mathrm{~min}$ at $16,000 \mathrm{rpm}$, and was then resuspended in buffer A containing $5 \mathrm{mM} \beta$-mercaptoethanol, $1 \mathrm{mM} \mathrm{L}-\mathrm{Arg}$, and $10 \mu \mathrm{M} \mathrm{H} \mathrm{H}_{4} \mathrm{~B}$. The resuspended solution was loaded onto a Ni-NTA-Sepharose CL-4B column that had been charged with $50 \mathrm{mM} \mathrm{NiSO}_{4}$ and equilibrated with buffer A containing $5 \mathrm{mM} \beta$-mercaptoethanol, $1 \mathrm{mM} \mathrm{L}$-Arg, and $10 \mu \mathrm{M} \mathrm{H}_{4} \mathrm{~B}$. The column was washed with 5 volumes of equilibration buffer and 5 volumes with equilibration buffer containing $10 \mathrm{mM}$ imidazole. The dNOSoxy protein was eluted with $100 \mathrm{mM}$ imidazole in buffer A. The eluted protein sample was dialyzed against buffer B (40 mM EPPS and 10\% glycerol) and then run onto a Q-Sepharose column equili- brated with buffer B containing $1 \mathrm{mM} \mathrm{L-Arg}$ and $10 \mu \mathrm{M}$ $\mathrm{H}_{4} \mathrm{~B}$. The bound protein was washed extensively with the equilibration buffer containing increasing concentrations of $\mathrm{NaCl}$, and the bound protein was eluted with Buffer $\mathrm{B}$ containing $200 \mathrm{mM} \mathrm{NaCl}$ plus L-Arg and $\mathrm{H}_{4} \mathrm{~B}$. The resulting protein sample was concentrated, dialyzed to remove the imidazole, and finally stored frozen in aliquots at $-80^{\circ} \mathrm{C}$.

UV-visible spectra of diluted protein samples were recorded on an Hitachi U3110 spectrophotometer in the absence or presence of $20 \mu \mathrm{M} \mathrm{H}_{4} \mathrm{~B}$ and $1 \mathrm{mM}$ Arg. Enzyme concentration was quantified using the absorption of the ferrous- $\mathrm{CO}$ adduct at $444 \mathrm{~nm}$ and an extinction coefficient of $74 \mathrm{mM}^{-1} \mathrm{~cm}^{-1}\left(A_{444}-A_{500}\right)$.

Preparation of Ferrous dNOSoxy. Concentrated dNOSoxy was placed in a cuvette and made anaerobic by several cycles of evacuation and purging with deoxygenated $\mathrm{N}_{2}$. An anaerobic solution that contained $50 \mathrm{mM}$ EPPS at $\mathrm{pH} 7.5$, $\mathrm{H}_{4} \mathrm{~B}$, and L-Arg or NOHA was then added. The enzyme was reduced by the sequential addition of a dithionite solution from which the concentration was standardized against ferricyanide. The heme reduction was monitored spectrophotometrically. The reduced enzyme solution was transferred into a syringe in a stopped-flow instrument using a gastight syringe.

Stopped-Flow Single Catalytic Turnover Reactions. RapidScanning stopped-flow experiments were performed at $10{ }^{\circ} \mathrm{C}$ using a HI-TECH SF-61 instrument equipped with a HI-TECH MG-6000 rapid-scanning diode-array detector, as described previously $(30,34,36)$. An anaerobic solution containing $50 \mathrm{mM}$ EPPS (pH 7.5), $10 \mu \mathrm{M}$ ferrous dNOSoxy, $10 \mu \mathrm{M} \mathrm{H}_{4} \mathrm{~B}$, and either $1 \mathrm{mM} \mathrm{L}$-Arg or $0.5 \mathrm{mM}$ NOHA was rapidly mixed with an equal volume of air-saturated buffer (50 mM EPPS at pH 7.5). Ninety-six scans from 350 to $700 \mathrm{~nm}$ were collected within 0.0018 to $2 \mathrm{~s}$ after each mixing. Sequential spectral data were fit to different reaction models using the Specfit global analysis program (provided by HiTech Ltd.), which can calculate the number of different enzyme species, their spectra, and their concentrations versus time during the single turnover reactions. Data from six to eight sequential reactions were averaged to obtain the final traces.

Product Stoichiometry Analyses. Amino acids in aliquots taken from single turnover reactions were derivatized with $o$-phthalaldehyde and then analyzed by reverse-phase HPLC with fluorescence detection (27). Samples were filtered through an Amicon Centricon device (10,000 MW cutoff) prior to derivatization. Samples were injected onto a HewlettPackard ODS-Hypersil column that was equilibrated with $5 \mathrm{mM}$ ammonium acetate at $\mathrm{pH} 6.0$ and $20 \%$ methanol and then subjected to an increasing gradient of methanol. Retention times and concentrations of amino acids were calculated on the basis of NOHA and citrulline standard solutions.

NO Binding Kinetics of Ferric NOSoxy Enzymes. The experiments were performed as previously described (51). An anaerobic solution containing $2 \mu \mathrm{M}$ of either dNOSoxy or nNOSoxy, $1 \mathrm{mM}$ Arg, $50 \mu \mathrm{M} \mathrm{H}_{4} \mathrm{~B}, 0.5 \mathrm{mM}$ EDTA in $40 \mathrm{mM}$ EPPS at pH 7.6 was rapidly mixed at $10{ }^{\circ} \mathrm{C}$ in the stopped-flow instrument with a buffered solution containing different concentrations of NO. The NO solutions were made by diluting a buffered, NO-saturated solution in anaerobic buffer and assuming a NO concentration of $1.9 \mathrm{mM}$ for a 
saturated solution at $25^{\circ} \mathrm{C}$. Six to eight sequential reactions were run at each $\mathrm{NO}$ concentration and then averaged to obtain the final traces. Data were fit to a single or double exponential equation.

Ferrous Heme-NO Oxidation Rate. A solution of $8 \mu \mathrm{M}$ ferric dNOSoxy in a $40 \mathrm{mM}$ EPPS buffer ( $\mathrm{pH}$ 7.6), containing $1 \mathrm{mM} \mathrm{Arg}, 50 \mu \mathrm{M} \mathrm{H}_{4} \mathrm{~B}$, and $0.5 \mathrm{mM}$ EDTA, was made anaerobic in a sealed cuvette and reduced by adding a small amount of anaerobic sodium dithionite solution at $10{ }^{\circ} \mathrm{C}$. To minimize adding excess dithionite, titration of the ferric enzyme was stopped as soon as the heme became reduced, as judged by a shift in the Soret absorbance and the disappearance of absorbance at $650 \mathrm{~nm}$. NO was subsequently added from a NO-saturated solution. The ferrous heme-NO enzyme was transferred to the stopped-flow instrument and mixed at $10{ }^{\circ} \mathrm{C}$ with buffer containing various $\mathrm{O}_{2}$ concentrations and $40 \mathrm{mM}$ EPPS $(\mathrm{pH}$ 7.6), $1 \mathrm{mM} \mathrm{Arg,} 50 \mu \mathrm{M} \mathrm{H}_{4} \mathrm{~B}$, and $0.5 \mathrm{mM}$ EDTA. The kinetics of ferrous heme- $\mathrm{NO}$ oxidation was determined from the absorbance loss at $438 \mathrm{~nm}$ (ferrous heme-NO decay) and buildup at $396 \mathrm{~nm}$ (ferric heme buildup). Traces at both wavelengths were averaged from 6 to 10 individual reactions and were fit to a single-exponential function using software provided by the instrument manufacturer.

Computer Simulation of the Global Kinetic Model for NOS Catalysis. Simulations of the model in Figure 6 were done using kinetic values determined here or previously at $10{ }^{\circ} \mathrm{C}$ and by using Mathcad software as previously described in detail $(31,44,50)$. In the current simulations, the following parameter values were utilized: for dNOS, $k_{\text {cat1 }} 28 \mathrm{~s}^{-1}, k_{\text {cat2 }}$ $48 \mathrm{~s}^{-1}, k_{\mathrm{d}} 18 \mathrm{~s}^{-1}$, and $k_{\mathrm{ox}} 0.2 \mathrm{~s}^{-1}$; for $\operatorname{nNOS}(38), k_{\text {cat1 }}$ $18 \mathrm{~s}^{-1}, k_{\text {cat } 2} 29 \mathrm{~s}^{-1}, k_{\mathrm{d}} 5 \mathrm{~s}^{-1}$, and $k_{\text {ox }} 0.2 \mathrm{~s}^{-1}$. The heme reduction rate $\left(k_{\mathrm{r}}\right)$ was varied as described in the text, and we assumed a constant concentration of $\mathrm{O}_{2}(140 \mu \mathrm{M})$ and NADPH $(40 \mu \mathrm{M})$ and no buildup of NO in solution.

\section{RESULTS AND DISCUSSION}

Expression, Purification, and Spectral Properties. The oxygenase domain of the Drosophila melanogaster NO synthase (dNOSoxy) was overexpressed in E. coli BL21 Rosetta cells. The dNOSoxy protein had a His 6 tag at its $\mathrm{N}$-terminus to enable purification by nickel-nitriloacetic acid sepharose column chromatography. The average yield of purified dNOSoxy was 3 to $4 \mathrm{mg} / \mathrm{L}$ of culture, and the final protein was approximately $90 \%$ homogeneous as judged by the SDS-PAGE analysis (data not shown). The apparent molecular mass of the dNOSoxy was $76 \mathrm{kDa}$, which is in good agreement with the predicted size of the polypeptide based on the gene sequence.

Purification of dNOSoxy was done in the presence of L-Arg and $\mathrm{H}_{4} \mathrm{~B}$. The UV-visible spectrum of dNOSoxy showed a Soret peak at $396 \mathrm{~nm}$ (Figure 1), typical of mammalian NOS enzymes containing bound Arg and $\mathrm{H}_{4} \mathrm{~B}$ $(27,28)$ and of five-coordinate, high-spin heme-thiolate proteins in general. Reduction of dNOSoxy with dithionite caused the Soret band to shift to $414 \mathrm{~nm}$ (not shown), and subsequent addition of CO shifted the Soret band to $445 \mathrm{~nm}$ (Figure 1), confirming an intact heme-thiolate bond in dNOSoxy.

Single Catalytic Turnover Reactions of dNOSoxy. We utilized rapid-scanning stopped flow spectroscopy to docu-

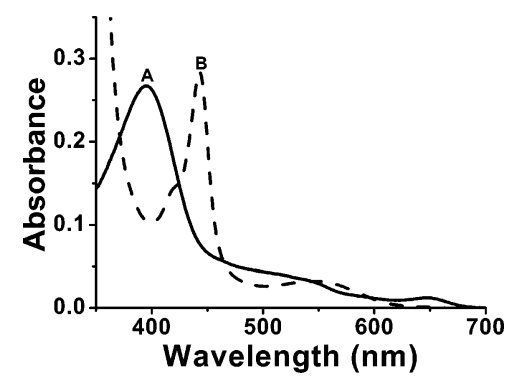

FIGURE 1: UV-visible spectra of purified dNOSoxy. Scan A is ferric dNOSoxy in the presence of $\mathrm{L}-\mathrm{Arg}$ and $\mathrm{H}_{4} \mathrm{~B}$, while scan $\mathrm{B}$ is the ferrous heme-CO complex.
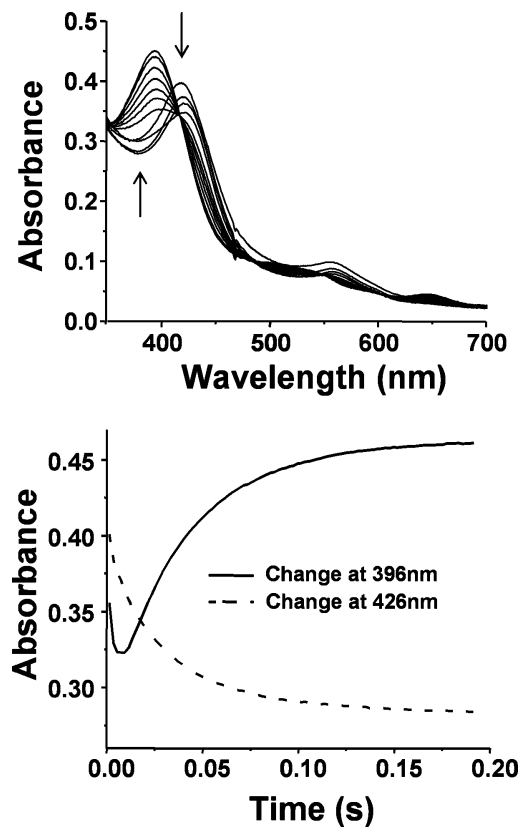

FIGURE 2: Kinetics of heme transitions during Arg oxidation by dNOSoxy under single turnover conditions. Anaerobic ferrous dNOSoxy containing Arg and $\mathrm{H}_{4} \mathrm{~B}$ was mixed at $10^{\circ} \mathrm{C}$ with airsaturated buffer in the stopped flow instrument to start the reaction. The upper panel contains spectral traces collected during the reaction and show the direction of absorbance change. The lower panel shows the absorbance change over time at two wavelengths. Data are representative of four independent experiments.

ment heme transitions during the Arg hydroxylation and NOHA oxidation reactions catalyzed by dNOSoxy. This approach has been quite valuable for understanding the reaction mechanism and kinetics of the mammalian NOS enzymes (29-31). Dithionite-reduced (ferrous) dNOSoxy that contained $\mathrm{H}_{4} \mathrm{~B}$ and either Arg or NOHA was rapidly mixed at $10{ }^{\circ} \mathrm{C}$ with an $\mathrm{O}_{2}$-saturated buffer to initiate the reaction.

For the Arg single turnover reaction, prior work with mammalian NOSoxy enzymes showed that a heme-dioxy intermediate is formed upon mixing reduced enzyme with $\mathrm{O}_{2}$-containing buffer, and then this species converts to ferric NOSoxy concurrent with Arg hydroxylation to form NOHA (30-32). However, in the Arg hydroxylation reaction of dNOSoxy, we observed no clear buildup of a heme-dioxy intermediate prior to the formation of ferric dNOSoxy (Figure 2). Global analysis of the spectral data also failed to indicate a clear buildup of a heme-dioxy intermediate in the reaction. This contrasts with the three mammalian NOSoxy enzymes, which typically build up a detectable heme-dioxy intermediate with characteristic heme Soret absorbance near $427 \mathrm{~nm}$ 
during the Arg hydroxylation reaction (29-32). Despite this, the shifting isosbestic points in Figure $2 \mathrm{~A}$ and the biphasic absorbance change at $396 \mathrm{~nm}$ in Figure 2B do suggest the formation of an intermediate in the reaction. Because the maximally shifted spectrum is centered at $420 \mathrm{~nm}$ in Figure $2 \mathrm{~A}$, it is possible that the dNOSoxy heme-dioxy intermediate formed in the Arg reaction is the $420 \mathrm{~nm}$ species that is observed for mammalian NOS enzymes under some conditions (52). In any case, we still could estimate the rate of Arg hydroxylation catalyzed by dNOSoxy from the concurrent loss of absorbance at $426 \mathrm{~nm}$ and the gain of absorbance at $396 \mathrm{~nm}$ (equivalent to the rate of ferric dNOSoxy formation) (Figure 2). The rates estimated at the two wavelengths were similar (29 $\mathrm{s}^{-1}$ and $26 \mathrm{~s}^{-1}$, respectively). These rates are in the high range of rates obtained for the heme-dioxy to ferric heme transition that is associated with Arg hydroxylation by the mammalian NOSoxy enzymes, which range from 6 to $24 \mathrm{~s}^{-1}$ under identical reaction conditions (37). Thus, dNOSoxy appears to catalyze Arg hydroxylation as fast or faster than most mammalian NOS enzymes and is most similar to nNOS in this respect.

Amino acid product analysis confirmed that dNOSoxy generated NOHA from Arg in the single turnover reactions (0.3 NOHA per heme). This product yield is within the range reported for Arg hydroxylation by mammalian NOSoxy enzymes under similar reaction conditions ( 0.2 to 0.8 NOHA per heme) $(32,34,35)$.

For the NOHA single turnover reaction of dNOSoxy, global analysis of the rapid scanning data indicated four consecutive heme species, which, on the basis of previous work with mammalian NOSoxy enzymes $(36,37)$, could be identified as the starting ferrous dNOSoxy, a transient hemedioxy intermediate, a ferric heme-NO intermediate, and the ferric dNOSoxy product. Thus, three observable transitions occurred during the NOHA oxidation reaction, where $k_{1}, k_{2}$, and $k_{3}$ are the calculated rates for the transitions:

$$
\mathrm{Fe}^{\mathrm{II}} \stackrel{k_{1}}{\longrightarrow} \mathrm{Fe}^{\mathrm{III}} \mathrm{O}_{2}^{-} \stackrel{k_{2}}{\longrightarrow} \mathrm{Fe}^{\mathrm{III}} \mathrm{NO} \stackrel{k_{3}}{\longrightarrow} \mathrm{Fe}^{\mathrm{III}}
$$

Figure 3 illustrates the UV-visible spectrum of the four enzyme species and the time course of their consecutive appearance and/or disappearance. The Soret absorbance peaks for the dNOSoxy $\mathrm{Fe}^{\mathrm{II}}, \mathrm{Fe}^{\mathrm{III}} \mathrm{O}_{2}{ }^{-}, \mathrm{Fe}^{\mathrm{III}} \mathrm{NO}$, and $\mathrm{Fe}^{\mathrm{III}}$ heme species were 415, 424, 438, and $396 \mathrm{~nm}$, respectively, which closely match the absorbance positions of these same species in mammalian NOSoxy enzymes when they catalyze NOHA oxidation $(34,36)$. Why a $428 \mathrm{~nm}$ ferrous-dioxy species was clearly observable in the NOHA reaction but not in the Arg reaction is puzzling and deserves further investigation. Our NOHA single turnover data imply that dNOS has a similar if not identical mechanism of catalysis compared to the mammalian enzymes. Amino acid product analysis confirmed that dNOSoxy generated citrulline from NOHA in the single turnover reactions ( 0.4 NOHA per heme), consistent with our observation of a buildup of a ferric heme-NO product complex during the reaction.

The calculated rates for the heme transitions observed during NOHA oxidation by dNOSoxy are listed in Table 1, along with values obtained for NOHA reactions catalyzed by the three mammalian NOSoxy enzymes and by one bacterial NOSoxy protein under identical or nearly identical
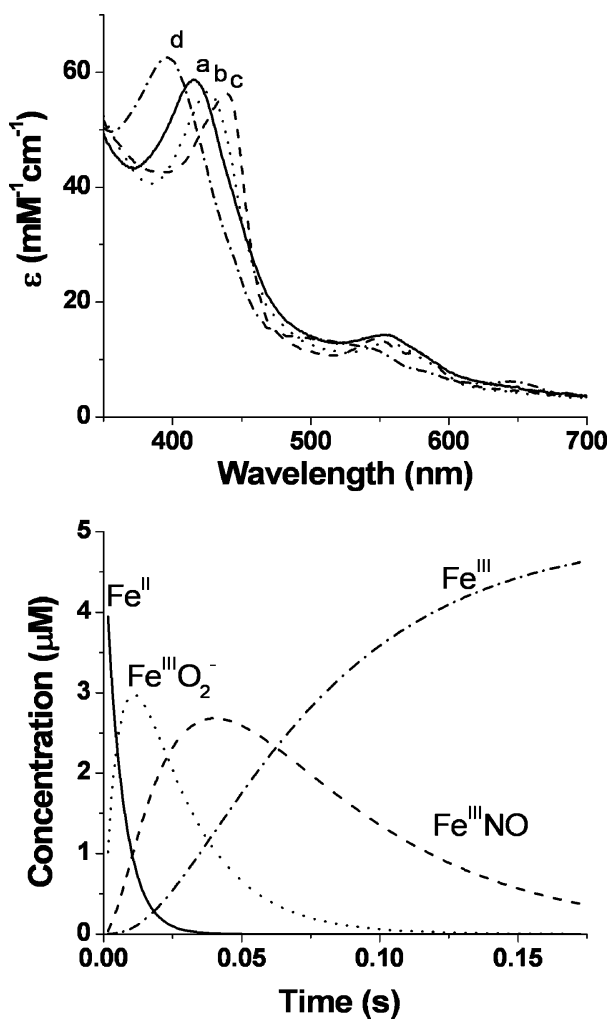

FIGURE 3: UV-visible spectra of heme species detected and their transition kinetics during NOHA oxidation by dNOSoxy under single turnover conditions. Anaerobic ferrous dNOSoxy containing NOHA and $\mathrm{H}_{4} \mathrm{~B}$ was mixed at $10{ }^{\circ} \mathrm{C}$ with air-saturated buffer in the stopped flow instrument to start the reaction. The upper panel contains spectra of four species derived from global analysis of the data. These in order of appearance are the ferrous (a, solid line), heme-dioxy (b, dotted line), ferric heme-NO (c, dashed line), and ferric (d, dash-dotted line) forms of dNOSoxy. The lower panel shows the kinetics of disappearance or formation of each spectral species. Line patterns for each species are the same as those in the upper panel. Data are an average of 6 to 10 reactions and are representative of four independent experiments.

reaction conditions $(17,34,36,38)$. The comparison shows that dNOSoxy has a rate of product formation as measured by the $k_{2}$ transition (also designated $k_{\text {cat }}$ ) that is as fast or faster than that in the mammalian and bacterial NOS enzymes $(30,36)$. The greatest difference, however, appears to be in the $k_{3}$ transition, which is the macroscopic dissociation rate $\left(k_{\mathrm{d}}\right)$ of the ferric heme-NO product complex that forms at the end of each catalytic cycle in all NOS enzymes examined to date $(31)$. This $k_{\mathrm{d}}$ is important because it helps to determine what percentage of the NO synthesized by a NOS enzyme is actually released into solution (39). Remarkably, the $k_{\mathrm{d}}$ values derived from our NOHA single turnover experiments indicate that $\mathrm{NO}$ dissociation from ferric dNOSoxy is 3 to 8 times faster than NO dissociation in the mammalian NOS enzymes and is 90 times faster than that in the bacterial NOS (Table 1).

To confirm whether dNOSoxy has a faster NO dissociation than the mammalian enzymes, we utilized a different stopped flow method (51) to compare the NO binding kinetics of ferric dNOSoxy and nNOSoxy. Each enzyme was mixed under pseudo-first-order conditions with solutions that contained different concentrations of $\mathrm{NO}$, and the observed $\mathrm{NO}$ binding rates were plotted versus the initial $\mathrm{NO}$ concentration (Figure 4). A slight deviation from a singleexponential fit was observed (particularly for the dNOSoxy 
Table 1: Observed Rates of Heme Transitions during NOHA Single Turnover Reactions Catalyzed by Various NOSoxy Enzymes ${ }^{a}$

\begin{tabular}{|c|c|c|c|c|c|}
\hline transformations & $\mathrm{dNOS} \mathrm{xy}^{b}$ & iNOSoxy $^{c}$ & $\mathrm{nNOSoxy}^{d}$ & eNOSoxy $^{e}$ & $\mathrm{bsNOS}^{f}$ \\
\hline heme-dioxy formation $\left(k_{1}\right)^{g}$ & $157 \pm 15$ & $47 \pm 4$ & $129 \pm 5$ & NA & $29 \pm 1$ \\
\hline $\begin{array}{l}\text { heme-dioxy disappearance or } \\
\mathrm{Fe}^{\mathrm{III}}-\mathrm{NO} \text { formation }\left(k_{2}, k_{\text {cat }}\right)\end{array}$ & $48 \pm 3$ & $37 \pm 1$ & $29 \pm 1$ & 18 & $7 \pm 1$ \\
\hline $\begin{array}{l}\mathrm{Fe}^{\mathrm{III}} \text {-NO disappearance or } \\
\text { ferric heme formation }\left(k_{3}, k_{\mathrm{d}}\right)\end{array}$ & $18 \pm 2$ & $2.3 \pm 0.1$ & $5 \pm 1$ & 3 & $0.2 \pm 0.1$ \\
\hline
\end{tabular}

${ }^{a}$ The rates were determined at $10{ }^{\circ} \mathrm{C}$ and are the mean \pm SD. ${ }^{b}$ This work. ${ }^{c}$ Wei et al., ref $36 .{ }^{d}$ Panda et al., ref $38 .{ }^{e}$ Unpublished observations. ${ }^{f}$ Adak et al., ref $17 .{ }^{g}$ Rates were recorded in a half $\mathrm{O}_{2}$-saturated reaction except for iNOSoxy and bsNOSoxy, which were recorded in a half air-saturated reaction. NA, not available.

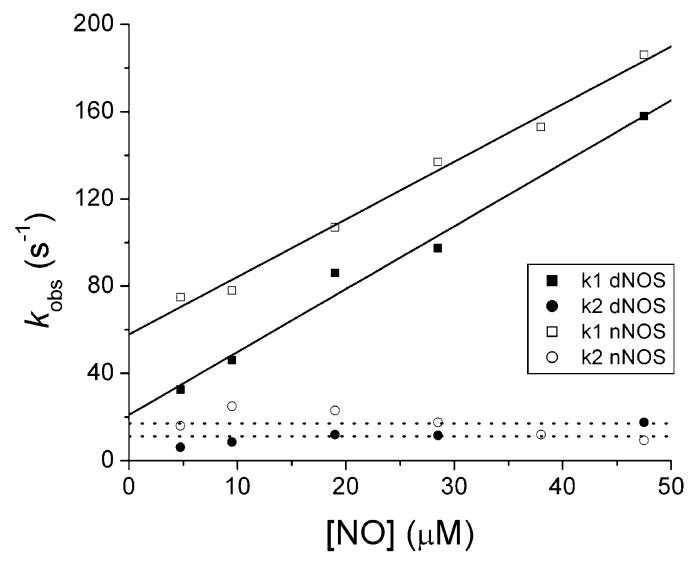

FIGURE 4: Kinetics of NO binding to dNOSoxy and nNOSoxy. An anaerobic solution of either ferric enzyme was mixed with NO containing solution in a stopped-flow spectrophotometer at $10{ }^{\circ} \mathrm{C}$ and the ferric heme-NO complex formation was monitored at $438 \mathrm{~nm}$. The absorbance traces were fit to a biexponential equation, and the observed rates are plotted vs the NO concentration with the least-squares lines of best fit as indicated. The data are representative of two independent experiments.

reactions), and therefore, for the sake of comparison both the nNOSoxy and dNOSoxy data were fit to a biexponential equation. The slower phase $\left(k_{2}\right)$ contributed $30 \%$ or less of the total absorbance change in all cases and appeared to be independent of NO concentration (Figure 4), whereas the fast phase $\left(k_{1}\right)$ was NO concentration-dependent. The $y$ axis intercepts of the $k_{1}$ rate data provide an estimate of the NO $k_{\mathrm{d}}$ for each ferric enzyme and are $21.0 \pm 5.5$ and $57.9 \pm$ $3.8 \mathrm{~s}^{-1}$ for dNOSoxy and nNOSoxy, respectively. These data are consistent with our NOHA single turnover experiments and confirm that ferric dNOSoxy has a faster NO $k_{\mathrm{d}}$ than the mammalian NOS enzymes.

In bacterial NOSoxy, we know that a Ile/Val substitution near the entrance to the heme pocket is partly responsible for its slow NO dissociation from the ferric heme (39). However, a protein sequence comparison (Figure S1, Supporting Information) reveals no obvious differences in the residues near the heme pockets of dNOSoxy and mammalian NOSoxy enzymes. This implies that the general dimensions and composition of the dNOSoxy heme pocket are similar to those in the mammalian NOSoxy enzymes $(28,39-41)$. Thus, faster NO dissociation from the dNOSoxy ferric heme could be due to other more global effects.

A second kinetic parameter that helps determine NOS catalytic behavior is the oxidation rate of the enzyme ferrous heme-NO complex. This complex forms whenever the ferric heme-NO product complex becomes reduced during steadystate turnover in the full-length NOS enzymes $(42-44)$. We studied this reaction in dNOSoxy by mixing the ferrous
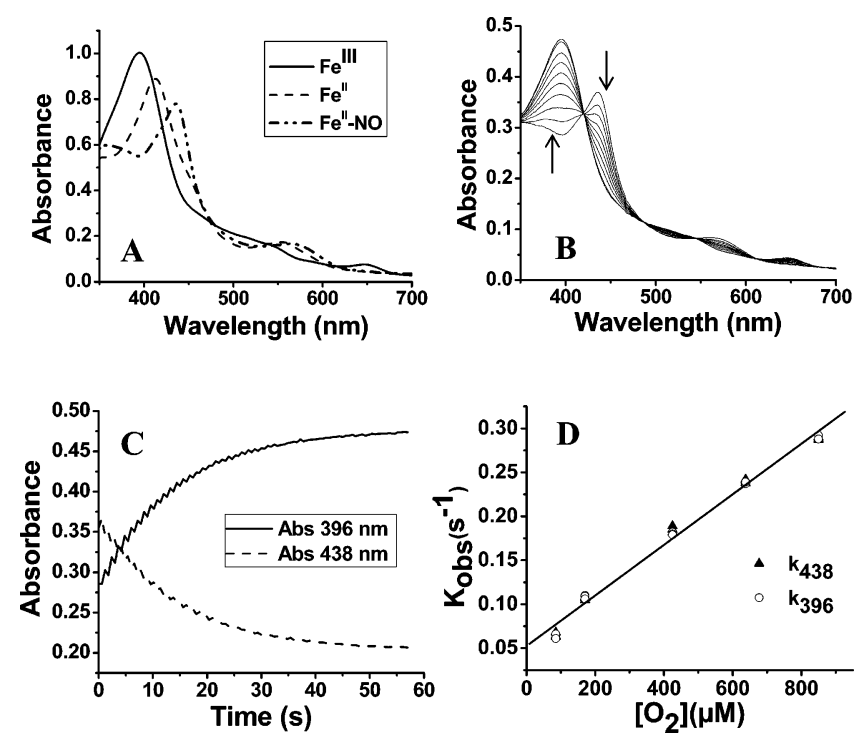

FIGURE 5: Oxidation of the dNOSoxy ferrous heme-NO complex. Panel A shows the UV-visible spectra of the ferric, ferrous, and ferrous-NO forms of dNOSoxy. Panel B contains spectral traces collected within $58 \mathrm{~s}$ after mixing the dNOSoxy ferrous hemeNO complex with air-saturated buffer in the stopped flow instrument at $10{ }^{\circ} \mathrm{C}$. Arrows indicate the direction of absorbance change with time. Panel $\mathrm{C}$ shows the absorbance changes at 438 and $496 \mathrm{~nm}$ vs time during the reaction of the dNOSoxy ferrous heme-NO complex with air-saturated buffer. Panel D plots the $k_{\text {obs }}$ values calculated from the absorbance changes at either wavelength for reactions that were performed at the different indicated concentrations of $\mathrm{O}_{2}$. The least-squares line of best fit is indicated. Data are the average of 6 to 10 individual reactions and are representative of three similar experiments.

heme-NO complex with oxygenated buffer at $10{ }^{\circ} \mathrm{C}$ in a stopped-flow spectrometer equipped with a diode-array detector. Figure 5, panel A shows the spectrum of authentic ferric, ferrous, and ferrous-NO forms of dNOSoxy. Panel B contains a group of consecutive spectral scans collected during a typical reaction. The several isobestic points indicate that a monophasic transition occurs between the starting ferrous heme-NO complex of dNOSoxy and the ending ferric enzyme, as is also reported for the reaction catalyzed by mammalian NOSoxy enzymes $(38,44)$. The rates of heme-NO complex disappearance and ferric enzyme formation were determined from the absorbance changes at 438 $\mathrm{nm}$ and at $396 \mathrm{~nm}$, respectively, and were best fit as monophasic transitions (Figure 5C). At the half air-saturated condition used here $\left(\mathrm{O}_{2}\right.$ concentration $\left.\sim 140 \mu \mathrm{M}\right)$, the oxidation rate of the dNOSoxy ferrous heme-NO complex (designated $k_{\mathrm{ox}}$ ) was $0.093 \mathrm{~s}^{-1}$ at $10{ }^{\circ} \mathrm{C}$. This rate is similar to that of the ferrous heme-NO complex of nNOSoxy at the same $\mathrm{O}_{2}$ concentration and temperature $\left(0.1\right.$ to $\left.0.2 \mathrm{~s}^{-1}\right)$ but is 6 and 13 times slower than the $k_{\text {ox }}$ rates measured for 
the ferrous heme-NO complexes of eNOSoxy and iNOSoxy, respectively $(44,45)$.

We went on to measure $k_{\mathrm{ox}}$ rates of dNOSoxy at various $\mathrm{O}_{2}$ concentrations. The rates we obtained are plotted in Figure 5D. The slope gives a second-order rate constant for the reaction of $290 \mathrm{M}^{-1} \mathrm{~s}^{-1}$. This value is quite similar to that obtained for mammalian nNOSoxy, whose $k_{\mathrm{ox}}$ second-order rate constant is $220 \mathrm{M}^{-1} \mathrm{~s}^{-1}$ at $10{ }^{\circ} \mathrm{C}$ (unpublished data). We conclude the ferrous heme- $\mathrm{NO}$ complex of dNOSr is relatively un-reactive toward $\mathrm{O}_{2}$ and in this way is similar to nNOSoxy.

Implications for the NO Synthesis Activity of dNOS. Our results provide two $\left(k_{\mathrm{d}}, k_{\mathrm{ox}}\right)$ of the three kinetic parameters that allow one to model and understand the catalytic behavior of any given $\operatorname{NOS}(31,44)$. The third variable is the heme reduction rate $\left(k_{\mathrm{r}}\right)$, which cannot be obtained using the isolated oxygenase or reductase domains of dNOS. However, even without a measured $k_{\mathrm{r}}$ value, we can still make reasonable predictions about the catalytic behavior of dNOS. Our data show that dNOS has a relatively fast $k_{\text {cat }}$ and a slow $k_{\mathrm{ox}}$ like nNOS. It also has a reductase domain whose electrontransfer properties and regulation (see the accompanying article) are similar to those of the nNOS reductase domain $(46,47,48)$. However, there is an important difference regarding the $k_{\mathrm{d}}$ values of ferric dNOS and nNOS that will distinguish their catalytic behaviors. For example, in nNOS, the rates of heme reduction $\left(k_{\mathrm{r}}, 3\right.$ to $\left.4 \mathrm{~s}^{-1}\right)$ and $\mathrm{NO}$ dissociation $\left(k_{\mathrm{d}}, 5 \mathrm{~s}^{-1}\right)$ are similar $(34,43)$. This causes its ferric heme-NO product complex to partition in about a 2:3 ratio between futile and productive cycles during catalysis (Figure 6A). Because nNOS has a relatively slow $k_{\text {ox }}(0.2$ $\mathrm{s}^{-1}$ ), a significant proportion of enzyme molecules accumulate as the ferrous heme-NO complex during steadystate NO synthesis $(31,44)$. This in turn compromises the observed NO synthesis activity of nNOS and greatly increases its apparent $K_{\mathrm{m}} \mathrm{O}_{2}$, enabling NOS to have a very gradual and near linear oxygen-NO synthesis activity response across the entire physiologic $\mathrm{O}_{2}$ concentration range $(31,49,50)$. In comparison, dNOS has a 5-times faster NO dissociation $\left(k_{\mathrm{d}}\right.$ is $\left.18 \mathrm{~s}^{-1}\right)$ that will predispose its ferric heme-NO product complex to release NO rather than become reduced to the ferrous heme-NO complex (Figure $6 \mathrm{~A})$. This means that at the heme reduction rate measured for nNOS (approximately $4 \mathrm{~s}^{-1}$ ), the $k_{\mathrm{d}}$ of dNOS would allow four enzyme molecules to release NO for every one molecule that enters the futile cycle and therefore should enable dNOS to have a greater NO synthesis activity than nNOS.

How the different $k_{\mathrm{d}}$ values will impact the catalytic behavior of dNOS and nNOS can be determined by computer simulation of the global kinetic model in Figure 6A $(44,50)$ using the kinetic values we have measured for dNOSoxy and nNOS $(44,50)$. We performed such simulations using the measured $k_{\mathrm{d}}$ values of 18 and $5 \mathrm{~s}^{-1}$ for dNOS and nNOS, respectively, a common $k_{\text {ox }}$ value of $0.2 \mathrm{~s}^{-1}$, and heme reduction rates $\left(k_{\mathrm{r}}\right)$ ranging from 0.3 to $12 \mathrm{~s}^{-1}$, which cover and exceed the known $k_{\mathrm{r}}$ values for NOS enzymes. Our simulations indicate that a smaller proportion of dNOS would exist as a ferrous heme-NO complex during the steady state compared to that of nNOS (Figure 6B). Moreover, dNOS would be up to 3.5 times more active than nNOS over the range of heme reduction rates (Figure 6C). Thus, a unique blend of kinetic parameters is likely to enable dNOS to be
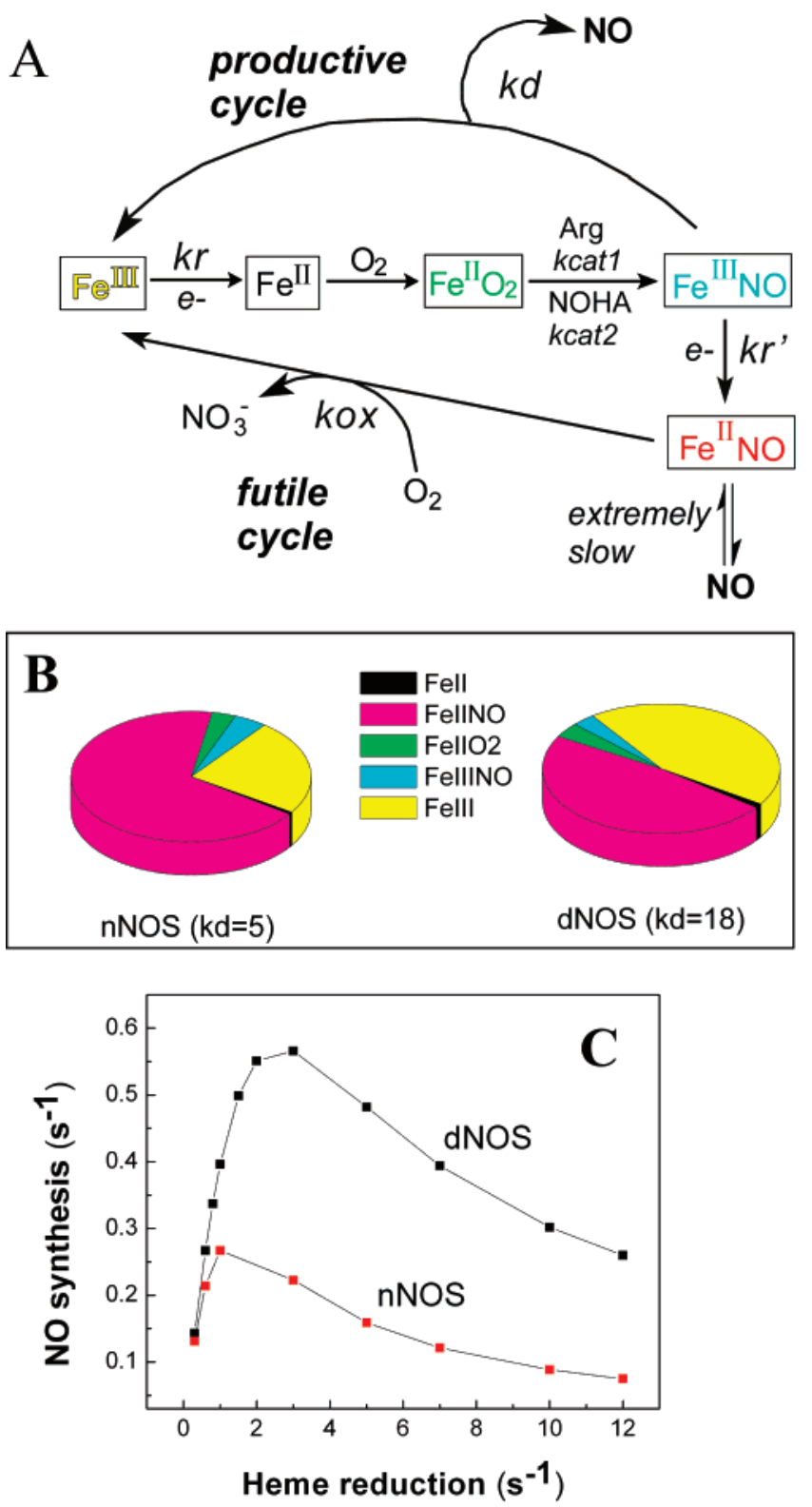

FIGURE 6: Global kinetic model for NOS catalysis and results derived from model simulations. Panel A shows that ferric enzyme reduction $(k r)$ is rate-limiting for the biosynthetic reactions (central linear portion). kcat 1 and kcat2 are the conversion rates of the $\mathrm{Fe}^{\mathrm{II}} \mathrm{O}_{2}$ species to products in the Arg and NOHA reactions, respectively. The ferric heme-NO product complex (Fe $\left.{ }^{\mathrm{III}} \mathrm{NO}\right)$ can either release $\mathrm{NO}(k d)$ in the productive cycle or become reduced $\left(k r^{\prime}\right)$ to a ferrous heme-NO complex ( $\mathrm{Fe}^{\mathrm{II} N O}$ ), which reacts with $\mathrm{O}_{2}$ (kox) to generate nitrate and ferric enzyme in the futile cycle. Panel B shows the calculated dNOS and nNOS enzyme distributions during steadystate NO synthesis at a common heme reduction rate of $3 \mathrm{~s}^{-1}$. Panel $\mathrm{C}$ plots the steady-state NO release rates as a function of $k r$ for $\mathrm{dNOS}$ and nNOS. Activities were calculated by simulation of the global kinetic model using parameters derived from dNOSoxy and nNOS. See Experimental Procedures for details.

a more active and efficient NO synthase than mammalian nNOS, while still allowing other important catalytic behaviors of the two enzymes $\left(\mathrm{Ca}^{2+}\right.$ concentration-activity response, $K_{\mathrm{m}} \mathrm{O}_{2}$ for $\mathrm{NO}$ synthesis) to remain similar. That dNOS would have a higher NO release capacity plus the regulatory mechanisms of a constitutive mammalian NOS (nNOS) makes some sense because Drosophila evolved to express a single NOS for both its cell signaling and host 
defense, while mammals utilize a different NOS for each purpose.

\section{ACKNOWLEDGMENT}

We thank Professor Brian Crane for helpful discussions.

\section{SUPPORTING INFORMATION AVAILABLE}

A sequence alignment of the Drosophila NOS oxygenase domain and other NOS sequences. This material is available free of charge via the Internet at http://pubs.acs.org.

\section{REFERENCES}

1. Stuehr, D. J., Wei, C. C., Wang, Z., and Hille, R. (2005) Exploring the redox reactions between heme and tetrahydrobiopterin in the nitric oxide synthases, Dalton Trans. 21, 3427-3435.

2. Marletta, M. A., Hurshman, A. R., and Rusche, K. M. (1998) Catalysis by nitric oxide synthase, Curr. Opin. Chem. Biol. 2, 656-663.

3. Hemmens, B., and Mayer, B. (1998) Enzymology of nitric oxide synthases, Methods Mol. Biol. 10, 1-32.

4. Forstermann, U, and Kleinert, H. (1995) Nitric oxide synthase: expression and expressional control of the three isoforms, NaunynSchmiedeberg's Arch. Pharmacol. 352, 351-364.

5. Dawson, V. L., and Dawson, T. M. (1998) Nitric oxide in neurodegeneration, Prog. Brain. Res. 118, 215-229.

6. Michel, T., and Feron, O. (1997) Nitric oxide synthases: which, where, how, and why? J. Clin. Invest. 100, 2417-2423.

7. Stuehr, D. J. (1999) Mammalian nitric oxide synthases, Biochem. Biophys. Acta 1411, 217-230.

8. Bredt, D. S., Hwang, P. M., Glatt, C. E., Lowenstein, C., Reed, R. R., and Snyder, S. H. (1991) Cloned and expressed nitric oxide synthase structurally resembles cytochrome P-450 reductase, Nature 351, 714-718.

9. Richards, M. K., Clague, M. J., and Marletta, M. A. (1996) Characterization of C415 mutants of neuronal nitric oxide synthase, Biochemistry 35, 7772-7780.

10. Sheta, E. A., McMillan, K., and Masters, B. S. S. (1994) Evidence for a bidomain structure of constitutive cerebellar nitric oxide synthase, J. Biol. Chem. 269, 15147-15153.

11. McMillan, K., and Masters, B. S. S. (1995) Prokaryotic expression of the heme- and flavin-binding domains of rat neuronal nitric oxide synthase as distinct polypeptides: identification of the hemebinding proximal thiolate ligand as cysteine-415, Biochemistry $34,3686-3693$.

12. Gachhui, R., Presta, A., Bentley, D. F., Abu-Soud, H. M., McArthur, R., Brudvig, G., Ghosh, D. K., and Stuehr, D. J. (1996) Characterization of the reductase domain of rat neuronal nitric oxide synthase generated in the methylotrophic yeast Pichia pastoris. Calmodulin response is complete within the reductase domain itself, J. Biol. Chem. 271, 20594-20602.

13. Vorherr, T., Knopfel, L., Hofmann, F., Mollner, S., Pfeuffer, T., and Carafoli, E. (1993) The calmodulin binding domain of nitric oxide synthase and adenylyl cyclase, Biochemistry 32, 60816088.

14. Rozhkova, E. A., Fujimoto, N., Sagami, I., Daff, S. N., and Shimizu, T (2002) Interactions between the isolated oxygenase and reductase domains of neuronal nitric-oxide synthase. Assessing the role of calmodulin, J. Biol. Chem. 277, 16888-16894.

15. Ghosh, D. K., Abu-Soud, H. M., and Stuehr, D. J. (1995) Reconstitution of the second step in NO synthesis using the isolated oxygenase and reductase domains of macrophage NO synthase, Biochemistry 34, 11316-11320.

16. Chen, P. F., Tsai, A. L., Berka, V., and Wu, K. K. (1996) Endothelial nitric-oxide synthase. Evidence for bidomain structure and successful reconstitution of catalytic activity from two separate domains generated by a baculovirus expression system, J. Biol. Chem. 271, 14631-14635.

17. Adak, S., Aulak, K. S., and Stuehr, D. J. (2002) Direct evidence for nitric oxide production by a nitric-oxide synthase-like protein from Bacillus subtilis, J. Biol. Chem. 277, 16167-16171.

18. Adak, S., Bilwes, A. M., Panda, K., Hosfield, D., Aulak, K. S., McDonald, J. F., Tainer, T. A., Getzoff, E. D., Crane, B. R., and Stuehr, D. J. (2002) Cloning, expression, and characterization of a nitric oxide synthase protein from Deinococcus radiodurans, Proc. Natl. Acad. Sci. U.S.A. 99, 107-112.

19. Wang, Z. Q., Lawson, R. J., Buddha, M. R., Wei, C. C., Crane, B. R., Munro, A. W., and Stuehr, D. J. (2007) Bacterial flavodoxins support nitric oxide production by Bacillus subtilis nitric-oxide synthase, J. Biol. Chem. 282, 2196-2202.

20. Wingrove, J. A., and O'Farrell, P. H. (1999) Nitric oxide contributes to behavioral, cellular, and developmental responses to low oxygen in Drosophila, Cell 98, 105-114.

21. Kuzin, B., Roberts, I., Peunova, N., and Enikolopov, G. (1996) Nitric oxide regulates cell proliferation during Drosophila development, Cell 87, 639-649.

22. Gibbs, S. M. (2003) Regulation of neuronal proliferation and differentiation by nitric oxide, Mol. Neurobiol. 27, 107-120.

23. Gibbs, S. M., and Truman, J. W. (1998) Nitric oxide and cyclic GMP regulate retinal patterning in the optic lobe of Drosophila, Neuron 20, 83-93.

24. Nappi, A. J., Vass, E., Frey, F., and Carton, Y. (2000) Nitric oxide involvement in Drosophila immunity, Nitric Oxide 4, 423-430.

25. Regulski, M., and Tully, T. (1995) Molecular and biochemical characterization of dNOS: a Drosophila $\mathrm{Ca} 2+/$ calmodulin dependent nitric oxide synthase, Proc. Natl. Acad. Sci. U.S.A. 92, 9072-9076.

26. Sengupta, R., Sahoo, R., Mukherjee, S., Regulski, M., Tully, T., Stuehr, D. J., and Ghosh, S. (2003) Characterization of Drosophila nitric oxide synthase: a biochemical study, Biochem. Biophys. Res. Commun. 306, 590-597.

27. Huang, L., Abu-Soud, H. M., Hille, R., and Stuehr, D. J. (1999) Nitric oxide-generated P420 nitric oxide synthase: characterization and roles for tetrahydrobiopterin and substrate in protecting against or reversing the P420 conversion, Biochemistry 38, 1912-1920.

28. Ghosh, S., Wolan, D., Adak, S., Crane, B. R., Kwon, N. S., Tainer, J. A., Getzoff, E. D., and Stuehr, D. J. (1999) Mutational analysis of the tetrahydrobiopterin-binding site in inducible nitric-oxide synthase, J. Biol. Chem. 274, 24100-24112.

29. Ledbetter, A. P., McMillan, K., Roman, L. J., Masters, B. S., Dawson, J. H., and Sono, M. (1999) Low-temperature stabilization and spectroscopic characterization of the dioxygen complex of the ferrous neuronal nitric oxide synthase oxygenase domain, Biochemistry 38, 8014-8021.

30. Wei, C. C., Wang, Z. Q., Wang, Q., Meade, A. L., Hemann, C., Hille, R., and Stuehr, D. J. (2001) Rapid kinetic studies link tetrahydrobiopterin radical formation to heme-dioxy reduction and arginine hydroxylation in inducible nitric-oxide synthase, J. Biol. Chem. 276, 315-319.

31. Stuehr, D. J., Santolini, J., Wang, Z. Q., Wei, C. C., and Adak, S. (2004) Update on mechanism and catalytic regulation in the NO synthases, J. Biol. Chem. 279, 36167-36170.

32. Hurshman, A. R., Krebs, C., Edmondson, D. E., Huynh, B. H., and Marletta, M. A. (1999) Formation of a pterin radical in the reaction of the heme domain of inducible nitric oxide synthase with oxygen, Biochemistry 38, $15689-15696$.

33. Berka, V., Wu, G., Yeh, H. C., Palmer, G., and Tsai, A. (2004) Three different oxygen-induced radical species in endothelial nitric-oxide synthase oxygenase domain under regulation by 1-arginine and tetrahydrobiopterin, J. Biol. Chem. 279, 3224332251.

34. Boggs, S., Huang, L., and Stuehr, D. J. (2000) Formation and reactions of the heme-dioxygen intermediate in the first and second steps of nitric oxide synthesis as studied by stopped-flow spectroscopy under single-turnover conditions, Biochemistry 39, $2332-2339$.

35. Bec, N., Gorren, A. C. F., Voelker, C., Mayer, B., and Lange, R. (1998) Reaction of neuronal nitric-oxide synthase with oxygen at low temperature evidence for reductive activation of the oxyferrous complex by tetrahydrobiopterin, J. Biol. Chem. 273, 13502-13508.

36. Wei, C. C., Wang, Z. Q., Hemann, C., Hille, R., and Stuehr, D. J. (2003) A tetrahydrobiopterin radical forms and then becomes reduced during $\mathrm{N}$-hydroxyarginine oxidation by nitric-oxide synthase, J. Biol. Chem. 278, 46668-46673.

37. Wei, C. C., Wang, Z. Q., Durra, D., Hemann, C., Hille, R., Garcin, E. D., Getzoff, E. D., and Stuehr, D. J. (2005) The three nitricoxide synthases differ in their kinetics of tetrahydrobiopterin radical formation, heme-dioxy reduction, and arginine hydroxylation, J. Biol. Chem. 280, 8929-8935.

38. Panda, K., Adak, S., Aulak, K. S., Santolini, J., McDonald, J. F., and Stuehr, D. J. (2003) Distinct influence of N-terminal elements 
on neuronal nitric-oxide synthase structure and catalysis, J. Biol. Chem. 278, 37122-37131.

39. Wang, Z. Q., Wei, C. C., Sharma, S., Pant, K., Crane, B. R., and Stuehr, D. J. (2004) A conserved Val to Ile switch near the heme pocket of animal and bacterial nitric-oxide synthases helps determine their distinct catalytic profiles, J. Biol. Chem. 279, 19018-19025.

40. Crane, B. R., Arvai, A. S., Ghosh, D. K., Wu, C., Getzoff, E. D., Stuehr, D. J., and Tainer, J. A. (1998) Structure of nitric oxide synthase oxygenase dimer with pterin and substrate, Science 279, 2121-2126.

41. Li, H., Igarashi, J., Jamal, J., Yang, W., and Poulos, T. L. (2006) Structural studies of constitutive nitric oxide synthases with diatomic ligands bound, J. Biol. Inorg. Chem. 11, 753-768.

42. Abu-Soud, H. M., Wang, J., Rousseau, D. L., Fukuto, J. M., Ignarro, L. J., and Stuehr, D. J. (1995) Neuronal nitric oxide synthase self-inactivates by forming a ferrous-nitrosyl complex during aerobic catalysis, J. Biol. Chem. 270, 22997-23006.

43. Adak, S., Santolini, J., Tikunova, S., Wang, Q., Johnson, J. D., and Stuehr, D. J. (2001) Neuronal nitric-oxide synthase mutant (Ser1412Asp) demonstrates surprising connections between heme reduction, NO complex formation, and catalysis, J. Biol. Chem. $276,1244-1252$.

44. Santolini, J., Meade, A. L., and Stuehr, D. J. (2001) Differences in three kinetic parameters underpin the unique catalytic profiles of nitric-oxide synthases I, II, and III, J. Biol. Chem. 276, 4888748898.

45. Adak, S., Wang, Q., and Stuehr, D. J. (2000) Molecular basis for hyperactivity in tryptophan 409 mutants of neuronal NO synthase, J. Biol. Chem. 275, 17434-17439.
46. Adak, S., Ghosh, S., Abu-Soud, H. M., and Stuehr, D. J. (1999) Role of reductase domain cluster 1 acidic residues in neuronal nitric-oxide synthase. Characterization of the FMN-free enzyme, J. Biol. Chem. 274, 22313-22320.

47. Knight, K., and Scrutton, N. S. (2002) Stopped-flow kinetic studies of electron transfer in the reductase domain of neuronal nitric oxide synthase: re-evaluation of the kinetic mechanism reveals new enzyme intermediates and variation with cytochrome $\mathrm{P} 450$ reductase, Biochem. J. 367, 19-30.

48. Konas, D. W., Zhu, K., Sharma, M., Aulak, K. S., Brudvig, G. W., and Stuehr, D. J. (2004) The FAD-shielding residue Phe ${ }^{1395}$ regulates neuronal nitric-oxide synthase catalysis by controlling NADP affinity and a conformational equilibrium within the flavoprotein domain, J. Biol. Chem. 279, 35412-35425.

49. Abu-Soud, H. M., Rousseau, D. L., and Stuehr, D. J. (1996) Nitric oxide binding to the heme of neuronal nitric-oxide synthase links its activity to changes in oxygen tension, J. Biol. Chem. 271, 32515-32518.

50. Santolini, J., Adak, S., Curran, C. M., and Stuehr, D. J. (2001) A kinetic simulation model that describes catalysis and regulation in nitric-oxide synthase, J. Biol. Chem. 276, 1233-1243.

51. Abu-Soud, H. M., Wu, C., Ghosh, D. K., and Stuehr, D. J. (1998) Stopped-flow analysis of $\mathrm{CO}$ and $\mathrm{NO}$ binding to inducible nitric oxide synthase, Biochemistry 37, 3777-3786.

52. Marchal, S., Gorren, A. C., Sorlie, M., Andersson, K. K., Mayer, B., and Lange, R. (2004) Evidence of two distinct oxygen complexes of reduced endothelial nitric oxide synthase, J. Biol. Chem. 279, 19824-19831.

BI700803P 